\title{
OPTIMALISASI PERAN SUAMI SEBAGAI PERSIAPAN PENDAMPING PERSALINAN MELALUI PRENATAL COUPLE YOGA DI WILAYAH YOGYAKARTA TAHUN 2018
}

\author{
Optimizing the Role of the Husband as Preparation for the Delivery Asistant \\ through Prenatal Couple Yoga in the Area of Yogyakarta in 2018 \\ Dheska Arthyka Palifiana1, Ratih Kumoro Jati² \\ Universitas Respati Yogyakarta, Universitas Jenderal Ahmad Yani Yogyakarta \\ (dheska87@gmail.com, ratihkumoro@yahoo.co.id)
}

\begin{abstract}
ABSTRAK
Latar Belakang: Persalinan merupakan proses alami yang akan dialami oleh setiap wanita, dan tidak bisa dipungkiri bahwa proses untuk menjadi seorang ibu adalah proses yang sangat mendebarkan dan penuh tantangan. Di Indonesia ibu hamil yang mengalami kecemasan dalam menghadapi persalinan sebanyak 107.000 orang $(28,7 \%)$. Dukungan yang diterima di lingkungan tempatnya melahirkan, termasuk dari mereka yang mendampinginya sangat mempengaruhi psikologisnya, maka ibu yang bersalin harus ditemani oleh orang yang dipercaya yaitu suaminya.

Tujuan: Penelitian ini bertujuan untuk mengetahui apakah ada pengaruh prenatal couple yoga terhadap pengetahuan dan kesiapan suami dalam persiapan menjadi pendamping persalinan di wilayah Yogyakarta Tahun 2018.

Metode: Jenis penelitian ini adalah Quasi experiment menggunakan rancangan one group pretest-posttest. Sampel penelitian ini adalah suami yang mengikuti prenatal couple yoga di wilayah Yogyakarta yang berjumlah 80 responden dengan teknik total sampling. Alat pengumpulan data menggunakan kuesioner. Analisis data menggunakan uji Chi Square.

Hasil: Pengetahuan suami tentang pendamping persalinan sebelum diberikan prenatal couple yoga sebagian besar dalam kategori kurang sebanyak 52 responden $(41,6)$ sedangkan sesudah diberikan prenatal couple yoga pengetahuan suami sebagian besar dalam kategori baik sebanyak 50 responden (40\%). Kesiapan suami dalam persiapan menjadi pendamping persalinan sebelum diberikan prenatal couple yoga sebagian besar dalam kategori kurang siap sebanyak 63 responden $(50,4 \%)$ sedangkan sesudah diberikan prenatal couple yoga sebagian besar dalam kategori siap sebanyak 60 responden (4\%). Ada pengaruh prenatal couple yoga terhadap pengetahuan suami tentang pendamping persalinan ( $\mathrm{p}$-value 0,000 ). Ada pengaruh prenatal couple yoga terhadap kesiapan suami menjadi pendamping persalinan ( $\mathrm{p}$-value 0,001 ).

Simpulan: Ada pengaruh prenatal couple yoga terhadap pengetahuan dan kesiapan suami dalam persiapan menjadi pendamping persalinan di wilayah Yogyakarta tahun 2018.
\end{abstract}

Kata kunci: Prenatal Couple Yoga, Pengetahuan, Kesiapan Suami, Pendamping Persalinan

Optimalisasi Peran Suami Sebagai Persiapan Pendamping Persalinan Melalui 


\begin{abstract}
Background: Labor is a natural process that will be experienced by every woman, and it cannot be denied that the process of becoming a mother is a very thri;;img and challenging process. In Indonesia pregnant women who experience anxiety in labor are as mani as 107.000 people. Support received in the environment where she gave birth, including those who accompanied her greatly afeccted her psychological, so the mother who gave birth had to be accompanied by someone who was trusted by her husband.

The Purpose: the study aims to determine whether there is an influence of prenatal couple yoga on the knowledge and readiness of the husband in preparation to become a labor companion in the Yogyakarta region in 2018.

Method: this type of research is Quasi Experiment using the design of one group pretest-posttest. The sample of this study was a husband who participated in prenatal couple yoga in the Yogyakarta area, amounting to 80 respondents with a total sampling technique. The data collection tool usess a questionnaire. Data analysis using Chi Square test.

Result: the husband's knowledge of the labor companion before being given a prenatal couple yoga is mostly in the less category as many as 52 responden $(41,6 \%)$ while after being given prenatal couple yoga the husband's knowledge is mostly in the good category as many as 50 responden (40\%). Husband's readiness in preparation to be a labor companion before being given a prenatal couple yoga is mostly in the category of unprepared as many as 63 responden $(50,4 \%)$ ehile after being given prenatal couple yoga most of them are in the prepared category as many as 60 responden (4\%). There is the influence of prenatal couple yoga on the husband's readiness to be a labor companion ( $p$-value 0,001 ).

Conclusion: there is the influence of prenatal couple yoga on the knowledge and readiness of the husband in preparation to become a labor companion in the Yogyakarta region in 2018.
\end{abstract}

Keyword: Prenatal Couple Yoga, Knowledge, Husband's Readiness, Childbirth Companion

\title{
PENDAHULUAN
}

Pada umumnya wanita yang sedang hamil takut menghadapi proses persalinan karena rasa sakit yang menimbulkan rasa takut dan cemas. Hal ini dapat menimbulkan ketegangan jiwa dan fisik yang akan mengakibatkan kakunya otot-otot dan persendian yang tidak wajar. Stress atau kecemasan tersebut terkait dengan berbagai hasil kehamilan, rasa sakit dan keluhan somatik lain yang sering terjadi dengan gangguan mood pada ibu hamil (Beddoe, 2009).

Didalam Making Pregnancy Safer (MPS) dijelaskan bahwa output yang diharapkan dari strategi sektor kesehatan secara terfokus pada pendekatan dan perencanaan yang sistematis dan terpadu adalah menetapkan keterlibatan suami dalam mempromosikan kesehatan ibu dan meningkatkan peran aktif suami dan keluarga dalam kehamilan dan persalinan (Rencana strategis : MPS, 2001). Dalam 
MPS dinyatakan pendekatan dalam meningkatkan partisipasi suami dalam kesehatan reproduksi adalah membekali suami dengan informasi dan mengikutsertakan suami dalam setiap upaya meningkatkan kesehatan reproduksi. Salah satu upaya kegiatan yang dapat dilakukan suami dalam upaya peningkatan kesehatan ibu dan anak adalah mendampingi istri selama proses persalinan dan mendukung rujukan bila diperlukan (Rencana strategis : MPS, 2001).

WHO telah merekomendasikan bahwa pendamping persalinan adalah atas pilihan ibu sendiri. Saat ini partisipasi suami dalam kesehatan reproduksi masih rendah. Pendamping, terutama orang terdekat ibu selama proses persalinan dapat membuat persalinan menjadi lebih singkat, nyeri berkurang, robekan jalan lahir jarang, sera nilai APGAR menjadi lebih baik. Masih banyak suami yang belum mampu menunjukkan dukungan penuh terhadap proses persalinan, di Indonesia terdapat $68 \%$ persalinan yang tidak didampingi suami selama proses persalinan (Darsana, 2009).

Kesiapan suami sebagai pendamping persalinan dirasakan sangat penting dalam membentuk perilaku seseorang, sehingga beberapa tempat bersalin di Indonesia membuat kebijakan untuk mengikutsertakan suami dalam asuhan kebidanan sebagai pendamping persalinan. Walaupun demikian kebijakan tersbut masih menyimpan keraguan diantara praktisi kesehatan terhadap kesiapan suami sebagai pendamping persalinan. Tenaga kesehatan ikut berperan serta untuk mempersiapkan suami sebagai pendamping persalinan yang baik sesuai dengan tujuan yang diharapkan oleh tenaga kesehatan (Widyaningsih, 2012).

Prenatal care merupakan hal yang sangat baik untuk mengatasi masalahmasalah selama kehamilan. Salah satu tujuannya adalah persalinan yang fisiologis dengan ibu dan anak yang sehat. Persalinan yang alami dan lancar ini dapat dicapai jika uterus berkontraksi dengan baik, ritmis dan kuat dengan segmen bawah rahim, serviks, dan otot-otot dasar panggul dalam keadaan relaksasi, sehingga bayi dengan mudah melewati jalan lahir. Keadaan ini dapat dicapai dengan bantuan wanita hamil itu sendiri yang merupakan ketenangan dan relaksasi tubuh yang sempurna (Kadek, 2011).

Salah satu intervensi yang dilakukan adalah latihan fisik seperti meditasi/yoga. Berlatih senam hamil yoga pada masa kehamilan merupakan salah satu solusi self help yang menunjang proses kehamilan, kelahiran dan bahkan pengasuhan anak yang dapat dilakukan dalam kelas antenatal, yang merupakan sarana untuk belajar kelompok tentang kesehatan ibu hamil dalam bentuk tatap muka yang bertujuan meningkatkan pengetahuan dan ketrampilan mengenai kehamilan, persalinan, perawatan nifas dan perawatan bayi baru lahir (Depkes, 2010).

Prenatal couple yoga merupakan salah satu modifikasi dari prenatal yoga. Prenatal couple yoga adalah yoga kehamilan dengan melibatkan suami, di dalam prenatal couple yoga pasangan suami istri juga diberikan materi-materi tentang persiapan dalam menghadapi persalinan dan juga yoga berpasangan suami istri.Prenatal couple yoga diadakan oleh tim dari Klinik Pratama Asih Waluyo Jati sebanyak empat kali dimana pesertanya berasal dari berbagai wilayah di Yogyakarta. 
Hasil studi pendahuluan dengan wawancara pada 10 suami yang sedang mendampingi istrinya memeriksakan kehamilan di Klinik Pratama Asih Waluyo Jati didapatkan bahwa 8 suami mengatakan belum mengetahui tentang persiapan apa saja yang harus disiapkan untuk menjadi pendamping persalinan dan mereka mengatakan cemas, takut dan belum siap untuk mendampingi istrinya dalam persalinan nanti. Sedangkan 2 orang suami mengatakan sudah mengetahui dan mempunyai pengalaman dalam mendampingi istrinya melahirkan anak yang sebelumnya.

Berdasarkan uraian diatas, maka peneliti tertarik untuk mengetahui "Pengaruh Prenatal Couple Yoga terhadap Pengetahuan dan Kesiapan Suami dalam Menjadi Pendamping Persalinan di Wilayah Yogyakarta Tahun 2018”.

\section{METODE PENELITIAN}

Penelitian ini merupakan penelitian quasi ekspriment dengan menggunakan rancangan one group pretest-posttest. Sampel penelitian ini adalah seluruh suami yang mengikuti prenatal couple yoga yang berjumlah 80 responden.

Pada penelitian ini menggunakan alat pengumpul date berupa kuesioner pengetahuan tentang pendamping persalinan dan kuesioner tentang kesiapan menjadi pendamping persalinan. Metode pengumpulan data yang digunakan adalah pengumpulan data primer. Dalam penelitian ini pengumpulan data primer dilakukan dengan membagikan kuesioner secara langsung kepada suami yang mengikuti prenatal couple yoga. Kuesioner diberikan sebelum dan sesudah diberikan prenatal couple yoga (pretest dan posttest). Analisa data dalam penelitian ini menggunakan Uji Chi Square.

\section{HASIL DAN PEMBAHASAN}

Tabel 1 Distribusi Frekuensi Variabel Pengetahuan Suami tentang Pendamping Persalinan sebelum diberikan Prenatal Couple Yoga

\begin{tabular}{ccc}
\hline Pengetahuan & Frekuensi (f) & Prosentase (\%) \\
\hline Baik & 8 & 6,4 \\
Cukup & 20 & 16,0 \\
Kurang & 52 & 41,6 \\
Total (n) & 80 & 100 \\
\hline
\end{tabular}

Tabel 1 diatas menunjukkan bahwa pengetahuan suami tentang pendamping persalinan sebelum diberikan prenatal couple yoga sebagian besar dalam kategori kurang sebanyak 52 responden $(41,6 \%)$ sedangkan sebagian kecil dalam kategori pengetahuan baik sebanyak 8 responden $(6,4 \%)$.

Tabel 2 Distribusi Frekuensi Variabel Pengetahuan Suami tentang Pendamping Persalinan sesudah diberikan Prenatal Couple Yoga

\begin{tabular}{ccc}
\hline Pengetahuan & Frekuensi (f) & Prosentase (\%) \\
\hline Baik & 50 & 40,0 \\
Cukup & 28 & 22,4 \\
Kurang & 2 & 1,6 \\
Total (n) & 80 & 100 \\
\hline
\end{tabular}

Optimalisasi Peran Suami Sebagai Persiapan Pendamping Persalinan Melalui 
Tabel 2 diatas menunjukkan bahwa pengetahuan suami tentang pendamping persalinan sesudah diberikan prenatal couple yoga sebagian besar dalam kategori baik sebanyak 50 responden $(40,0 \%)$ sedangkan sebagian kecil dalam kategori pengetahuan kurang sebanyak 2 responden $(1,6 \%)$.

Tabel 3 Distribusi Frekuensi Variabel Kesiapan Suami dalam Menghadapi Persalinan sebelum diberikan Prenatal Couple Yoga

\begin{tabular}{ccc}
\hline Kesiapan & Frekuensi (f) & Prosentase (\%) \\
\hline Siap & 17 & 13,6 \\
Kurang Siap & 63 & 50,4 \\
Total (n) & 80 & 100 \\
\hline
\end{tabular}

Tabel 3 diatas menunjukkan bahwa kesiapan suami dalam menghadapi persalinan sebelum diberikan prenatal couple yoga sebagian besar dalam kategori kurang siap sebanyak 63 responden $(50,4 \%)$ sedangkan sebagian kecil berada dalam kategori siap sebanyak 17 responden $(13,6 \%)$.

Tabel 4 Distribusi Frekuensi Variabel Kesiapan Suami dalam Menghadapi Persalinan sesudah diberikan Prenatal Couple Yoga

\begin{tabular}{ccc}
\hline Kesiapan & Frekuensi (f) & Prosentase (\%) \\
\hline Siap & 75 & 60,0 \\
Kurang Siap & 5 & 4,00 \\
Total (n) & 80 & 100 \\
\hline
\end{tabular}

Tabel 4 diatas menunjukkan bahwa kesiapan suami dalam menghadapi persalinan sesudah diberikan prenatal couple yoga sebagian besar dalam kategori siap sebanyak 75 responden $(60 \%)$ sedangkan sebagian kecil berada dalam kategori kurang siap sebanyak 5 responden (4\%).

Tabel 5 Pengaruh Prenatal Couple Yoga terhadap Pengetahuan Suami tentang Pendamping Persalinan di Wilayah Yogyakarta Tahun 2018

\begin{tabular}{llcccccccc}
\hline No & $\begin{array}{l}\text { Prenatal } \\
\text { Couple }\end{array}$ & \multicolumn{3}{c}{ Pengetahuan Suami tentang Pendamping } & \multicolumn{3}{c}{ Jumlah } \\
& Yoga & \multicolumn{2}{c}{ Persalinan } & \multicolumn{3}{c}{ Baik } & \multicolumn{2}{c}{ Cukup } & \multicolumn{2}{c}{ Kurang } & & \\
& & $\mathrm{n}$ & $\%$ & $\mathrm{n}$ & $\%$ & $\mathrm{n}$ & $\%$ & $\mathrm{n}$ & $\%$ \\
\hline 1 & Sebelum & 8 & 6,4 & 20 & 16,0 & 52 & 41,6 & 80 & 100 \\
2 & Sesudah & 50 & 40,0 & 28 & 22,4 & 2 & 1,6 & 80 & 100 \\
\multicolumn{2}{l}{ Hasil Uji Chi-Square $\mathrm{p}=0,00<\mathrm{a}=0,05$} & & & & & &
\end{tabular}

Berdasarkan tabel 5 diketahui bahwa terjadi peningkatan pengetahuan suami tentang pendamping persalinan dimana sebelum diberikan prenatal yoga sebagian besar dalam kategori kurang sebanyak 52 responden $(41,6 \%)$ dan sebagian kecil dalam kategori baik sebanyak 8 responden $(6,4 \%)$. Sedangkan pengetahuan suami tentang pendamping persalinan sesudah dilakukan prenatal couple yoga sebagian besar dalam kategori baik sebanyak 50 responden $(40,0 \%)$ dan sebagian kecil dalam kategori kurang sebanyak 2 responden $(1,6 \%)$.

Hasil analisis menggunakan uji Chi-Square dengan $\mathrm{a}<0,05$ didapatkan $\mathrm{p}=0,00$ berarti kurang dari 0,05 maka dapat disimpulkan bahwa hipotesis diterima yang artinya ada pengaruh yang bermakna antara prenatal couple yoga terhadap pengetahuan suami tentang pendamping persalinan di WilayahYogyakarta tahun 2018 . 
Avicenna Journal of Health Research. Vol 2 No 1. Maret 2019 ( 1 -9)

Tabel 6. Pengaruh Prenatal Couple Yoga terhadap Kesiapan Suami dalam persiapan menjadi pendamping persalinan

\begin{tabular}{|c|c|c|c|c|c|c|c|}
\hline \multirow[t]{3}{*}{ No } & \multirow[t]{3}{*}{$\begin{array}{l}\text { Prenatal Couple } \\
\text { Yoga }\end{array}$} & \multicolumn{4}{|c|}{$\begin{array}{l}\text { Kesiapan Suami dalam Persiapan } \\
\text { menjadi Pendamping Persalinan }\end{array}$} & \multicolumn{2}{|c|}{ Jumlah } \\
\hline & & \multicolumn{2}{|c|}{ Siap } & \multicolumn{2}{|c|}{ Kurang Siap } & \multirow[b]{2}{*}{$\mathrm{n}$} & \multirow[b]{2}{*}{$\%$} \\
\hline & & $\mathrm{n}$ & $\%$ & $\mathrm{n}$ & $\%$ & & \\
\hline 1 & Sebelum & 17 & 13,6 & 75 & 60,0 & 80 & 100 \\
\hline 2 & Sesudah & 63 & 50,4 & 5 & 4,00 & 80 & 100 \\
\hline \multicolumn{6}{|c|}{ Hasil Uji Chi-Square $p=0,001<a=0,05$} & & \\
\hline
\end{tabular}

Berdasarkan tabel 6 diketahui bahwa kesiapan suami dalam persiapan menjadi pendamping persalinan terjadi peningkatan sebelum dan sesudah diberikan prenatal couple yoga. Sebelum diberikan prenatal couple yoga kesiapan suami sebagian besar dalam kategori kurang siap sebanyak 75 responden $(60 \%)$ dan sebagian kecil dalam kategori siap sebanyak 17 responden $(13,6 \%)$. Sedangkan sesudah diberikan prenatal couple yoga kesiapan suami sebagian besar dalam kategori siap sebanyak 63 responden $(50,4 \%)$ dan sebagian kecil dalam kategori kurang siap sebanyak 5 responden (4\%).

Hasil uji statistik menggunakan Chi-Square dengan $\mathrm{a}<0,05$ didapatkan $\mathrm{p}=0,001$ berarti kurang dari 0,05 maka dapat disimpulkan bahwa hipotesis diterima yang artinya ada pengaruh yang bermakna antara prenatal couple yoga terhadap kesiapan suami dalam persiapan menjadi pendamping persalinan di Wilayah Yogyakarta Tahun 2018.

Hasil penelitian pada tabel 1 dapat dilihat bahwa pengetahuan suami tentang pendamping persalinan sebelum diberikan prenatal couple yoga dengan kategori pengetahuan baik sebanyak 8 responden $(6,4 \%)$, pengetahuan cukup sebanyak 20 responden (16\%) dan pengetahuan kurang sebanyak 52 responden $(41,6 \%)$. Sedangkan hasil penelitian pada tabel 2 dapat dilihat bahwa pengetahuan suami sesudah diberikan prenatal couple yoga dengan kategori baik sebanyak 50 responden $(40 \%)$, pengetahuan cukup sebanyak 28 responden $(22,4 \%)$ dan pengetahuan kurang sebanyak 2 responden $(1,6 \%)$.

Pengetahuan adalah hasil "tahu" dan ini terjadi setelah orang melakukan penginderaan terhadap suatu objek tertentu. Pengetahuan merupakan segala sesuatu yang diketahui oleh orang yang didapat secara formal dan informal. Pengetahuan formal dapat diperoleh dari pendidikan sekolah sedangkan pengetahuan informal diperoleh dari luar sekolah. Pengetahuan informal dapat diperoleh dari media informasi atau media elektronika maupun dari pengalaman diri sendiri atau orang lain (Soekanto, 2009). Sebagian besar pengetahuan suami sebelum diberikan prenatal couple yoga dalam kategori kurang sebanyak 52 responden. Kurangnya pengetahuan suami tentang pendamping persalinan bisa disebabkan karena berbagai faktor diantaranya sebagian besar adalah suami yang istrinya baru pertama kali hamil sehingga suami belum mempunyai pengalaman dalam mendampingi istri melahirkan. Pengetahuan merupakan hal yang penting dalam menentukan sebuah sikap dan tindakan karena dari pengalaman ternyata pengetahuan yang baik akan menentukan sikap dan tindakan yang baik pula (Notoatmodjo, 2010). selain karena belum mempunyai pengalaman dalam mendampingi persalinan karena masih anak pertama para suami juga belum 
pernah mendapatkan konseling tentang persiapan apa saja yang diperlukan suami untuk menjadi pendamping persalinan.

Secara umum persalinan merupakan proses membuka dan menipisnya serviks dari janin turun ke dalam jalan lahir. Persalinan dan kelahiran normal adalah proses pengeluaran janin yang terjadi pada kelahiran cukup bulan (37-42), lahirs spontan dengan presentase belakang kepala, tanpa komplikasi baik ibu maupun janin (Prawirohardjo, 2005). Proses persalinan yang mulai dari kala I sampai kala IV merupakan proses yang panjang yang dimana seorang ibu membutuhkan seorang pendamping yang mampu mengurangi rasa sakit yang ibu rasakan pada saat menjalankan proses persalinan tersebut, disinilah peran suami sebagai pendamping yang sangat berpengaruh pasa psikologi ibu, namun kehadiran suami dalam proses persalinan cenderung membutuhkan sebuah bekal pengetahuan dan dengan pengetahuan itu suami mampu memposisikan diri sebagai pendamping untuk membantu mengurangi rasa sakit yang dirasakan ibu pada proses persalinan terutama pada primigravida namun tidak menutup kemungkinan yang multigravida pun akan mengalami hal yang sama sakitnya walupun pernah ada pengalaman sebelumnya.

Ditengah kondisi yang tidak nyaman, istri memerlukan pegangan, dukungan dan semngat untuk mengurangi kecemasan dan ketakutannya. Pendamping persalinan baik itu suami, keluarga, atau ibu akan selalu ada bila dibutuhkan, dengan berada disamping istri yang sedang melahirkan, keluarga maupun suami siap membantu apa saja yang dibutuhkan istri. Manfaat lain adalah kedekatan emosi suami-istri akan bertambah saat suami melihat sendiri perjuangan sang istri saat melahirkan anaknya yang dapat membuat suami semakin dekat dan sayang kepada istrinya (Indriyani, 2014).

Hasil penelitian pada tabel 3 dapat dilihat bahwa kesiapan suami dalam persiapan menjadi pendamping persalinan sebelum diberikan prenatal couple yoga sebagian besar dalam kategori kurang siap sebanyak 63 responden $(50,45)$ dan dalam kategori siap sebanyak 17 responden $(13,6 \%)$. Sedangkan hasil penelitian pada tabel 4 dapat dilihat bahwa kesiapan suami dalam persiapan menjadi pendamping persalinan sesudah diberikan prenatal couple yoga sebagian besar dalam kategori siap sebanyak 75 responden (60\%) dan dalam kategori kurang siap sebanyak 5 responden (4\%).

Pendamping persalinan adalah seorang yang dapat berbuat banyak untuk dapat membantu ibu saat persalinan. Pendamping merupakan keberadaan seorang yang mendampingi atau terlibat langsung sebagai pemandu persalinan, yang mendukung selama kehamilan, persalinan dan nifas agar proses persalinan yang dilaluinya berjalan dengan lancar dan memberi kenyamanan bagi ibu bersalin. Suami merupakan calon terkuat yang akan menjadi pendamping persalinan (Danuatmaja, 2008). Sebelum diberikan prenatal couple yoga kesiapan suami untuk menjadi pendamping persalinan sebagian besar dalam kategori kurang siap sebanyak 63 responden, hal ini disebabkan karena sebagian besar suami belum pernah mendampingi istrinya di ruang bersalin.

Pendamping persalinan harus ditentukan jauh sebelum hari persalinan dan pastikan pendamping persalinan cukup usia, cukup matang, dan memiliki kesiapan mental untuk mendukung ibu secara emosional. Dalam hal ini, suami 
dapat menjadi calon terkuat untuk mendampingi ibu, karena ikatan emosional istri dan suami memang lebih kuar dibandingkan dengan keluarga lainnya. Suami bertanggung jawab penuh atas keselamatan istri dan anaknya. Sebagai pendamping persalinan, suami seharusnya membekali dirinya dengan hal-hal berikut yaitu siap mengajukan pertanyaa, membawa bekal untuk diri sendiri, mengetahui hal apa yang akan dihadapi, bersikap fleksibel, menemukan pengalihan perhatian, menjadi supporter ibu, mengetahui kapasitas sebagai pendamping, bersiap mengambil alih, siap menunggu dan selalu disamping ibu (Bobak, 2005).

Berdasarkan hasil penelitian tabel 5 didapatkan bahwa ada pengaruh prenatal couple yoga terhadap pengetahuan suami tentang pendamping persalinan dengan p-value 0,000 .

Didalam prenatal couple yoga selain pasangan suami istri diajari untuk beryoga bersama juga diberikan materi-materi seputar persiapan untuk menghadapi persalinan. Pengetahuan bukanlah sesuatu yang sudah ada dan tersedia, sementara orang lain tinggal menerimanya, pengetahuan adalah sebagai suatu pembentukan yang terus menerus oleh seseorang yang setiap saat mengalami reorganisasi karena adanya pemahaman-pemahaman baru (Budi, 2013). Kehadiran suami tanpa harus ada tekanan dari luar. Proses persalinan akan sangat penting dalam membantu istri terutama banyak mengetahui tentang fisiologi persalinan dan banyak tahu tentang persalinan. Suami tidak akan membantu jika kehadirannya tidak diinginkan oleh suami itu sendiri, kehadiran suami dalam proses persalinan harus atas dasar kemauannya sendiri, sehingga ada rasa tanggung jawab dalam perannya sebagai pendamping (Anggraeni, 2014).

Hasil penelitian tabel 6 didapatkan bahwa ada pengaruh prenatal couple yoga terhadap kesiapan suami dalam persiapan menjadi pendamping persalinan dengan p-value 0,001 .

Suami sebagai pendamping persalinan ikut memainkan peranan penting dalam mengikuti seluruh proses persalinan. Berbagai cara yang dilakukan suami saat mendampingi persalinan antara lain mengukur lamanya waktu kontraksi, bernapas seirama, membantu menopang istrinya, memberi pijatan lembut pada punggung atau perut ibu, menyuguhkan minum, menyampaikan pesan istri kepada petugas kesehatan, memberikan perhatian dan mendorong semangat (Yanti, 2009). Sebagian besar suami sebelum diberikan prenatal couple yoga mempunyai kesiapan yang kurang siap hal ini dikarenakan sebagian besar responden tidak siap secara usia, mental, dan kurang paham dengan peran yang seharusnya dilakukan dalam mendampingi persalinan nantinya.

\section{SIMPULAN DAN SARAN}

\section{Simpulan}

Pengetahuan suami tentang pendamping persalinan sebelum diberikan prenatal couple yoga sebagian besar dalam kategori kurang sebanyak 52 responden $(41,6 \%)$. Pengetahuan suami tentang pendamping persalinan sesudah diberikan prenatal couple yoga sebagian besar dalam kategori Baik sebanyak 50 responden (40\%). Ada pengaruh prenatal couple yoga terhadap pengetahuan 
suami tentang pendamping persalinan di Wilayah Yogyakarta tahun 2018 dengan nilai $\mathrm{p}$-value $0,000<0,05$. Ada pengaruh prenatal couple yoga terhadap kesiapan suami dalam persiapan menjadi pendamping persalinan di wilayah Yogyakarta Tahun 2018 dengan nilai p-value $0,001<0,05$.

\section{Saran}

Bagi fasilitas kesehatan di wilayah Yogyakarta dari hasil penelitian ini diharapkan dapat memberikan masukan bagi tenaga kesehatan untuk lebih mempersiapkan suami sebagai calon pendamping persalinan sehingga tercipta persalinan yang nyaman dan minim trauma.

\section{DAFTAR PUSTAKA}

Anggraeni, Diana Septi. 2014. Pengaruh Dukungan Suami dalam Proses Persalinan dengan Nyeri Persalinan di RSIA Bunda Arif Purwokerto. Jurnal Kebidanan, Vol. 5 No. 1 Edisi Juni. (diakses 20 Februari 2019).

Beddoe, AE. 2009. The Effects of Mindfulness-Based Yoga During Pregnancy on Maternal Psychological and Physical Distress. J obstet Gynecol Neonatal Nurs. http://jognn.awhonn.org.

Bobak, Lowdermilk. 2005. Buku Ajar Keperawatan Maternitas. Jakarta: Swara.

Danuatmadja, B. 2008. Persalinan Normal Tanpa Rasa Sakit. Jakarta: Puspa Swara.

Darsana. 2009. Pendamping Persalinan. Jakarta: EGC.

Depkes, RI. 2010. Strategi Akselerasi Pencapaian target MDGs 2015. http://www.target_mdgs.Pdf. (Diakses 20 Februari 2019).

Indriyani, Farihah. 2014. Pengaruh Pendamping Persalinan dan Paritas terhadap Pengurangan Rasa Nyeri Kala I Fase Aktif pada Ibu Bersalin Normal di RSIA Adina Wonosobo. Jurnal Kebidanan Panti Wilasa, Vol. 3 No. 1 Oktober 2012 (Diakses 20 Februari 2019).

Kadek, W. 2011. Manfaat Prenatal Yoga terhadap Proses Persalinan. Ungaran. Stikes Ngudi Waluyo.

Notoatmodjo, Soekidjo. 2010. Ilmu Perilaku Kesehatan Edisi Revisi. Jakarta: PT Renika Cipta.

Soekanto, Soejono. 2006. Sosiologi Suatu Pengantar. Jakarta : PT Raja Grafindo Persada.

Widyaningsih, R. 2008. Sikap Suami sebagai Pendamping Persalinan. Skripsi: Jakarta.

Yanti. 2009. Buku Ajar Asuhan Kebidanan Persalinan. Yogyakarta : Pustaka Rihama. 